\section{Performing in Extreme Environments} Lawrence E. Armstrong

Champaign, IL: Human Kinetics, 2000

US \$19.95, CAN \$29.95, 333 pages, softcover

Lawrence Armstrong has written an interesting book on human performance in extreme environments. These "extreme environments" include the usual heat, cold, hyperbaric, and high-altitude stresses that we are interested in most often. However, he has also added sections on "other" environmental stresses such as air pollution, weather patterns and air ions, and biorhythmic disturbances.

This book is written specifically for athletes, soldiers, or laborers who may be asked to perform in any of these stressful environments. The writing is easy to understand and follows a logical path, as the stresses are addressed individually and, when appropriate, in conjunction with other stresses. The information is presented at an introductory college level and makes very good use of figures and tables to illustrate the message.

Each chapter deals with the physiological responses to various stresses and then provides practical advice for work and training in various conditions. Each chapter comes with a valuable list of references that will aid a more in-depth look at the issues. The author has obvious research expertise in the areas of heat stress, air pollution, and the effect of ions on health and performance. Unfortunately, some of the other chapters have some inaccuracies or errors. For example, shivering actually commences as soon as skin temperature decreases and not after core temperature drops to $36^{\circ} \mathrm{C}$. Shivering heat production can also account for up to $40 \%$ of maximal exercise heat production, so it is quite a substantial source of heat for hypothermia prevention.

This book would make good reading for the armchair physiologist. It could even be used as an introductory text for an environmental physiology course, assuming the instructor's ability to recognize and correct errant information for the students.

Gordon Giesbrecht, $\mathrm{PhD}$ Winnipeg, Manitoba, Canada 